Kelley Racicot, Washington State University

Charles Pezeshki, Washington State University 


\title{
Assessing Group Learning Using Wikis: An Application to Capstone Design
}

\begin{abstract}
In this paper, we discuss the use of a wiki for documenting social knowledge in the context of an industrially-based capstone design course and for assessing group learning. Students create a knowledge management (KM) tool for the explicit purposes of sharing lessons learned with wider audiences and engaging in active group assessment, where students actively develop the product to be assessed. Because students are encouraged to verbalize in their own words concepts learned in class, the wiki reinforces learning and serves as a formative assessment tool, or perception check, for students and professors. This case analysis involved collecting feedback from key stakeholders, including Advisory Board and Industrial Sponsor interviews, student focus group discussions and assessment surveys. In addition, the wiki itself serves as a summative assessment tool. A difference approach was used to analyze rater perceptions of actual and expected performance. An average improvement score, based on a rubric, was obtained that minimizes unreliability for small, variable groups like advisory boards.
\end{abstract}

\section{Introduction}

New, creative uses of web-based group platforms, such as wikis and weblogs in industry and education, have been adopted for project management, to support "folio thinking", to encourage reflective practice and to build communities of practice. This qualitative and quantitative study looks at the pilot semester of using social software in a wellestablished senior capstone design course to support collaborative knowledge management and group assessment. We want to answer the question: How do we assess team or group learning?

From this research question, we developed three project goals:

1. Leverage the group-editing capabilities of WSU Wiki to facilitate a new course dimension: collaborative knowledge management.

2. Pilot the use of social software as a tool for assessing group learning and performance.

3. Collect feedback from students, College Advisory Board members and Industrial Project Sponsors in order to assess student performance and meta-level project efficacy.

\section{Background: The Capstone Industrial Design Clinic}

Team-oriented student design ${ }^{3}$ has been part of this ABET-certified mechanical engineering program for many years. In its current form in the School of Mechanical and Materials Engineering at Washington State University, for the past 10 years, student groups work on revenue-sponsored engineering projects ( $\$ 60-\$ 80,000$ annually) for industry partners. The projects are completed in one semester. Students are responsible 
for every aspect of project management, from scoping to production, including budget, travel, and business communication.

Clinic sustainability is achieved through a philosophy that clinic director Pezeshki humorously calls "the circle of treats," whereby every stakeholder invested in the program gets something of value from it. It is within this decision-making framework that the wiki project was launched. Students potentially benefit from learning important knowledge management skills and engaging in untapped peer-learning opportunities. Industry stakeholders and faculty potentially benefit from a new assessment approach and improved team performance.

In order to fulfill the project goals, the social software WSU Wiki ${ }^{14}$ was adopted for use in the class. WSU Wiki is a site for WSU students, faculty, staff and alumni to collaboratively develop hyper-linked documents for the purpose of growing communities of practice across courses, programs, and disciplines. WSU Wiki appeared to be a practicable and exciting tool to launch our project.

WSU Wiki was put into production fall 2005 at Washington State University by WSU's Center for Teaching, Learning and Technology. It uses the same open-source software, MediaWiki, that powers online encyclopedia Wikipedia ${ }^{12}$. The wiki is organized into individual "article" pages, each of which is put into one or more category. Category pages automatically index articles within that category. Every article page has a discussion page "behind" it for discussion and feedback. Article pages also have history pages with an archived list of contributors and versions. Users can search their contributions across articles and versions can be compared using the dif function.

WSU Wiki uses an editor that functions much like a word processor, but requires "wiki markup" language for formatting. For example, "*" creates a bulleted item or "==" creates a new section. Users can also create User Pages, which are publicly viewable but can only be edited by the user. This function was not employed in the pilot project, but holds great promise for assessing individual performance and group performance in the same environment.

In addition to WSU Wiki, which was used solely for Knowledge Management (KM) in the class, the commercial Project Management (PM) software application, Basecamp, was also utilized. Basecamp is a commercially available web-based project management system that provides basic PM functions such as calendaring, messaging, and grouping and is relatively inexpensive. Basecamp is used to manage the day-to-day project activities, such as creating to-do lists, scheduling activities, and monitoring project milestones. All students, corporate sponsors, staff and faculty upload their contact information and photos. The entire project history is archived at the end of each semester.

The Industrial Design Clinic serves other purposes besides giving students an opportunity to master engineering design. Engineering graduates are increasingly expected to have the social and "soft skills" necessary to be successful on the job. While the clinic 
provided real opportunities for students to learn social skills during their practicum, they had few opportunities to share their experiences with each other, future participants, or the public. A course website was difficult to maintain, chronically out-of-date and ultimately abandoned.

The wiki is intended to give the Industrial Design Clinic an archival memory of social information that is independent of the instructor. Such a contribution is extremely valuable in the Capstone Design context, as students that take the class one semester typically graduate at the end and the sum of their personal experiences is lost. Student participants craft narratives in their own words about academic topics and personal experiences. Short activity prompts are used as scaffolding, after which the students assume control of the structure and nature of their wiki contributions.

During the Fall 2005 semester, 25 students in two sections spent one hour per week, for eight weeks, on the wiki project. We collected interview and survey data from three College of Mechanical and Materials Engineering Advisory Board members and three Industrial Project Sponsors during campus visits. We also collected focus group data from design students. Student artifacts and usages are available online ${ }^{14}$.

\section{Literature Review}

One of the project goals was to develop tools for assessing group learning. This has historically been a difficult task. The term "group assessment" is defined loosely in the literature. Our study looks to both organizational studies as well as education research for the definition. The "ecosystem" perspective in business is at the forefront of organizational studies ${ }^{10}$. Managers place a high value on social and "soft skills," as well as content-specific knowledge. They are interested in group learning and the social construction of knowledge $\mathrm{e}^{2,5,10}$. If a business goes belly-up, for example, it is generally regarded as a failure of the group, not an individual.

Educators, because of the individual nature of the grading system and implicit reward structure in academic culture, focus on individual performance to the extreme. This has led to a dearth of research on group learning that is based on group performance criteria. Many studies have focused on the positive effects of group work on individual performance and the sum of individuals' artifacts to support program evaluation ${ }^{8}$. The lack of assessment tools for group learning has hampered the adoption of progressive group-based pedagogies.

One of the strengths of using social software to support group assessment is that its architecture is extremely flexible and diffuse. Wikis provide an easy way for nontechnical users to publish writing, links, images, etc., to the World Wide Web using a web browser. Looking at Wikipedia, for example, authors collectively contribute and maintain articles that are multi-disciplinary and freely hyperlinked. Wikis have been used successfully in engineering classrooms as a design tools ${ }^{13}$ and to support reflective learning activities ${ }^{1}$. 
Portfolios for teaching, learning, assessment, and evaluation are being widely researched and put into practice. Reflective artifacts based on individual learning outcomes and performance criteria underpin the "folio thinking" concept ${ }^{1}$. Relatively unpracticed is a strategy rooted in Quality Management $(\mathrm{QM})^{9}$, whereby formative and summative group assessments, supported by group artifacts, are reviewed by multiple stakeholdersstudents, faculty, administrators and practitioners from business and industry.

In the group assessment framework, group criteria are explicit and individual criteria are implicit. Potential benefits include: (1) students focus on the "good of the group," rather than grading, pleasing the instructor, or superficial aspects of individual assessment criteria (2) program faculty have evidence to support their answer to the question: how do you show that your program is doing a better job?

\section{Methods}

The democratic architecture of wikis holds great potential for collaborative learning, but presents challenges during start-up. There is a learning curve associated with wiki markup, editing and linking pages, and organizing articles into categories. We helped students get started by creating a course page that included short start-up activities, help information and announcements. This page evolved into an index of student articles that are both course-related and searchable in the greater wiki landscape. For example, the Conference Calls article page is linked to the ME_416_Pezeshki page. It is also indexed in the Social Skills category, which is not course-specific.

The wiki uniquely supports both face-to-face and distance (online) collaboration for any size group. Students and the instructor spent 15-20 minutes each one-hour class period discussing weekly progress and new topics. A consensus process was used to decide what new topics would be posted the following week and to delegate tasks. Students spent the remaining time on task. Most of the students worked in small groups of 2-3 per computer and occasionally by themselves.

Students were encouraged to post articles of interest. Instructors also prompted discussions on topics relevant to the course, such as writing case studies, providing Strength, Improvement, Insight ${ }^{11}$ (SII) feedback to peers, and interviewing for a job. The job interview discussion, for example, happened during a week of on-campus interviews and two groups contributed to an article on the topic that week.

\section{Instruments}

Three instruments were used to collect data: (1) Industry/Advisory Board survey, questionnaire and interview; (2) student focus group discussion; and (3) an online wiki archive. These instruments were selected based on best-practice methodologies in education assessment ${ }^{8}$ and best fit for the scope of the study.

Three College Advisory Board members and three Industrial Partners were invited to review the wiki project and provide feedback. A six-point Likert-type scale was used to 
separately rate student performance and expected performance of first-year engineers in seven performance areas (Appendix A). The raters were then asked to provide SII feedback for the wiki project. The seven dimensions are based on existing course outcomes, plus new project and knowledge management dimensions. Space was provided for additional comments related to each dimension and 15 minutes were allotted for discussion following the rating session.

A second data set was obtained by interviewing 18 design students in two focus groups. The focus group discussions were conducted in the design lab classroom by the first author during regular class time. Focus Group questions are listed in Appendix B. The question pool was based on the need to understand what was learned, what worked, what didn't and how to improve the program.

Wiki artifacts include 23 article pages written by 25 design students. Appendix C shows a table summarizing major category and article pages.

\section{Results}

We tracked instructor versus student contributions on the main page in order to assess how effective our scaffolding was in moving students to "own" the project (Figure 4.1). Ten individuals and one instructor edited the Index Page. By mid-semester students assumed responsibility for the online management of the wiki.

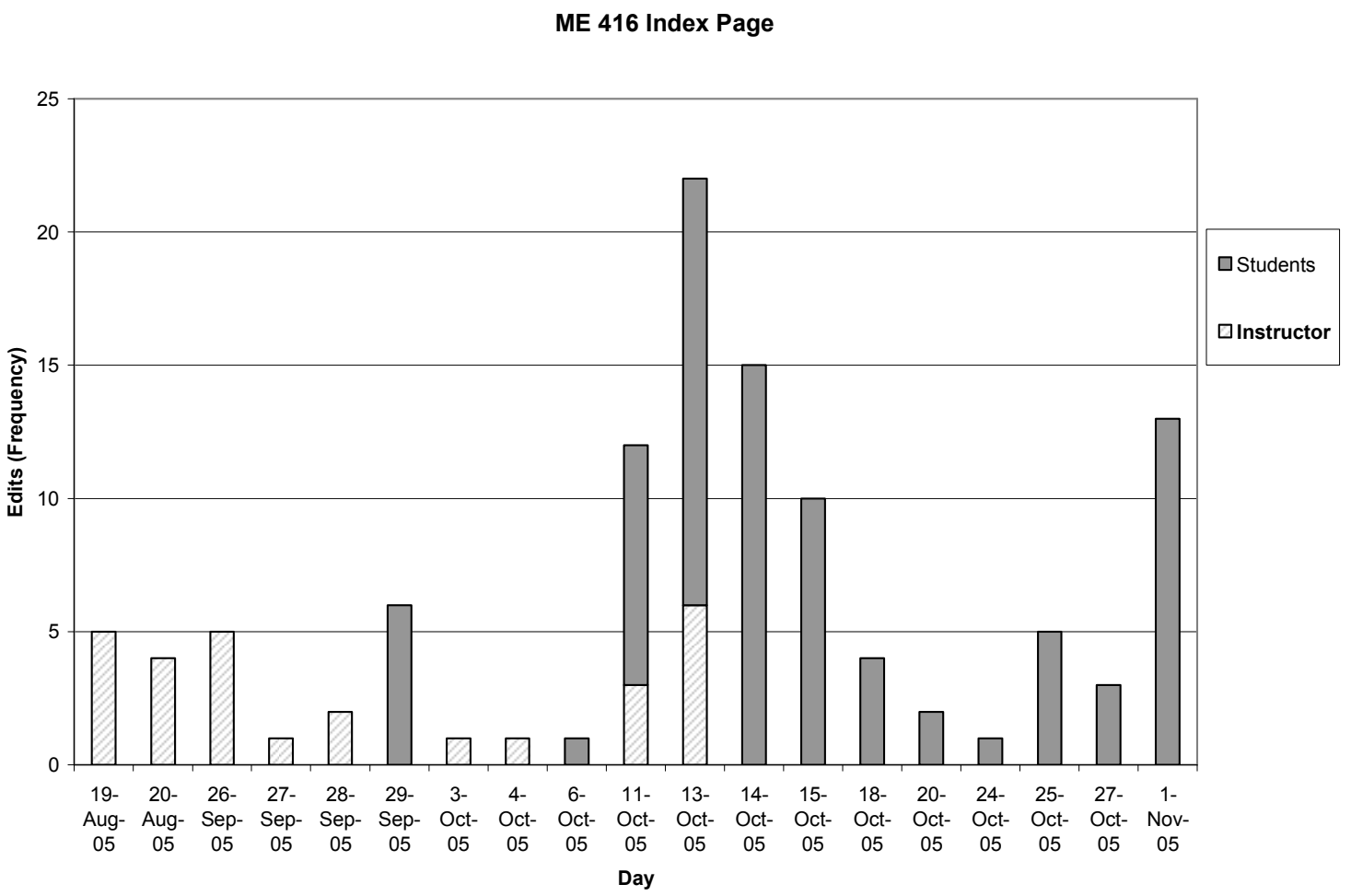

Figure 4.1: Instructor and student edits to the capstone Index page in chronological order. 


\section{Survey results}

Time constraints dictated that we were unable to use the test-re-test method for determining reliability among the raters and our sample size, $\mathrm{N}=6$, was small. We chose not to use a consensus-based norming session to improve inter-rater reliability because we wanted to measure first impressions. Instead, we measured the difference between rater perceptions of actual and expected performance. We averaged the scores to determine the category of average actual performance and average expected performance for each question. Because each rater brings different assumptions about what these categories mean in the "real" and "academic" world, we calculated the difference between actual and expected ratings for each question and determined the average delta, or "room for improvement."

Table 4.1 shows a summary of the average performance category for students, average expected performance category for first-year engineers, and the average difference between the average performance rating and expected performance rating for each question.

\begin{tabular}{|c|c|c|c|}
\hline \multicolumn{4}{|c|}{ Rating key: (1-2) emerging (3-4) developing (5-6) mastering } \\
\hline Dimension & $\begin{array}{l}\text { Ave. } \\
\text { Performance }\end{array}$ & $\begin{array}{l}\text { Ave. } \\
\text { Expected }\end{array}$ & Ave. dif \\
\hline a) group interaction & developing & developing & -0.5 \\
\hline $\begin{array}{l}\text { b) written engineering } \\
\text { communication }\end{array}$ & developing & developing & -0.5 \\
\hline $\begin{array}{l}\text { c) safety, ethical, and societal } \\
\text { constraints }\end{array}$ & emerging & emerging & -0.4 \\
\hline d) integrating ideas & developing & developing & -1.1 \\
\hline $\begin{array}{l}\text { e) corporate etiquette and } \\
\text { "customer" ethic }\end{array}$ & developing & developing & -0.3 \\
\hline f) project management & emerging & emerging & +0.4 \\
\hline g) knowledge management & emerging & developing & -0.1 \\
\hline
\end{tabular}

Table 4.1: Summary of the average difference between actual and expected performance ratings

\section{Survey findings}

Six of the seven average performance ratings fell into the same performance-level category as the average expected ratings. Knowledge management was the exception, as first-year engineers were rated developing and students were rated at the emerging level. This is supported by a negative average difference, which indicates a consensus among raters that they would want to see improvement in this dimension.

Six of the seven average differences are negative, indicating that raters would like to see improvements in these areas. Integrating ideas is in the developing category for both actual and expected performance. This dimension has the largest negative average 
difference, which suggests that raters see the greatest need for improvement in this dimension.

Project management is in the emerging category for both actual and expected performance, yet it has a +0.4 average difference. Two possible reasons for this were surfaced in this study. First, in practice, employers don't see many engineering graduates with project management skills. Expectations for performance in emerging fields tend to be low relative to the high need. Second, the wiki project provides a meta-level view of project management using BaseCamp, thus the expectations for the wiki project to meet specific project management outcomes are low. Interview and focus group questions suggest that students and raters believe wiki knowledge management and BaseCamp project management are complementary but serve different purposes. Those findings are summarized in rater and student perceptions.

\section{Rater perceptions}

Raters responded positively to the Wiki project overall, indicating that graduates with KM experience would be highly valued in industry. Rater responses are summarized in Appendix D. Raters identified strengths in three general categories: (1) archived knowledge; (2) peer communication; and (3) flexible systems. Raters agreed that the wiki is a great way to pass on "tribal knowledge" from one class to the next that would otherwise be lost. Raters also indicated that peer sharing is an important KM attribute, i.e. that much of the advice is in "student-speak." The flexible nature of the wiki was identified as an important aspect of this project. Students have access to the material " $24 / 7$ " and it makes sharing information easy and quick.

Raters identified how to improve in three general categories: (1) scaffolding; (2) motivation; and (3) dissemination. Raters indicated that it was important for students to understand the need for KM in industry and that a more explicit approach to providing background information, such as examples and articles, might be helpful. Raters wanted to know what motivates students to contribute to the wiki and how to help students get started when later groups will benefit more from the information in the wiki than the pilot group. Improving dissemination was identified as an important aspect of the wiki

project. Inviting student clubs and other classes to participate was one suggestion. Another was to archive engineering events, such as speeches at the annual Order of the Engineer dinner.

Rater insights included support for including the KM and wiki concepts in the curriculum across courses, introducing conflict resolution skills explicitly, and the need for an incentive structure for graduating seniors to "leave behind" their knowledge.

\section{Student author perceptions}

Focus group discussions were conducted at the end of the semester (Appendix E). Students were asked to compare and contrast KM and PM using wiki and Basecamp. Most agreed that "they are totally different" and complementary, suggesting that 
"BaseCamp is better for day to day management, wiki for long-term management." Students liked the concept of helping people "down the road." Students liked the flexibility of the wiki platform to independently organize and manage pages and unlimited access, even after graduation. Dislikes generally related to learning new software, user-unfriendliness, lack of pre-defined structure and lack of privacy.

Most students felt that the wiki project was academically and professionally relevant. Students said the wiki was important because it provides a record "beyond design factors" and a place to share information that BaseCamp didn't automatically archive. Students felt that the wiki project reinforced learning. Discussions, such as SII, "were helpful because they were something everyone can benefit from." Some students weren't sure that they would use the wiki, as they looked to experts, rather than peers, for information.

Based on SII feedback, most students found the activity prompts and supplemental materials helpful, such as editing help and case study writing tips. Students suggested that basic wiki markup be introduced earlier in the semester, when there is more time to learn the software and explore other successful wikis, such as Wikipedia. Most students agreed that continuing the wiki project would help others and that inviting student clubs to participate is a good idea. Many students were unsure about the expectations employers have for first-year engineers to have KM and PM skills and how the WSU wiki project would help them in their first year on the job.

\section{Discussion}

An important overarching concept was surfaced in this study: there is a substantive difference between active assessment and passive assessment. Passive assessment is the process of mining for finite artifacts, such as examining final papers after the semester has ended. Such final papers are written for the benefit of the student receiving the grade, and not with the improvement of the course or learning structure in mind. Students are passive - they are given assignments, they complete them, and they are not enfranchised in a direct way in the knowledge continuity or evolution of the class.

The development of a wiki for the purpose of assessment is fundamentally different. Students actively develop the product - the wiki - with the intent that it will be used for group assessment, improvement of the course, and the benefit of future students. Students and other stakeholders care very much about active assessment: learning, helping others, and partnership in design. Akin to the money-and-deliverable "circle of treats," active group assessment relies on the emotional, intellectual, and practical investment of students, faculty, programs and corporate interests. This social network is supported by an implicit incentive system that benefits everyone. Our study characterizes the incentive-benefit network of a small-scale group assessment project.

Another important concept is the development of an assessment technique for averaged group assessment when the concepts to be measured do not lend themselves easily to classical methods of testing and grading. Taking a client out to lunch may, in many 
ways, influence the success or failure of a professional's career more than remembering how to solve a complex integration problem-yet educational programs shy away from teaching the latter, in part because such skill sets are considered intangible and difficult to measure. Facilitating measurement of such tasks may influence the academy to add more such material in their curricula once accepted methods of charting progress are developed.

Difference analysis offers a way to quantize overall class learning by observing external advisor rubric/questionnaire deltas for actual and expected performance ratings. Processes such as ABET, as well as departmental internal audits, often use members of external advisory boards to determine if a program is "on track." but such surveys are highly variable. The wiki gives a fixed artifact of body of knowledge learned in the class and across courses. By utilizing the presented system of rubric/questionnaire deltas, an average improvement score, based on a rubric, can be obtained and compared crosssemester that minimizes unreliability for small groups like advisory boards. Advisory board memberships can be highly variable, and their memberships are usually filled with upper-level managers that have little time for standardizing their viewpoints with others on the board, or engaging in extensive evaluation training. Because of this, it is important to have a tool that normalizes rater perceptions without rater training.

Aside from use of the wiki as an assessment tool, one of the adjunct benefits is that it forces to students to verbalize concepts presented in class in their language. In our experience, students that cannot discuss a topic, regardless of nature (technical or nontechnical), do not understand that topic. In a larger culture that is known for its generation gaps, social software offers a mini- Rosetta Stone - a translational document between professors and students, who, while both might be speaking English, may not be speaking the same language. Since instructors do not contribute to wiki construction, other than providing material for the dominant schema and stubs, the resultant knowledge is expressed in ways that the students understand. Even the student-fashioned structure can give benefit to the students in giving them a schema for charting and retaining material in a class.

\section{Next Steps}

Students provided feedback for this study primarily from the wiki-author perspective. In Spring 2006, students will also provide feedback from the wiki-user perspective, as they will benefit from the previous semester's work. Additionally, a pre and post survey is being developed to gauge student perceptions of the importance of the seven rater dimensions in their academic and professional lives. Students will be asked to rate how important these skills are in their academic life, what skills an employer expects them to have in their first year, and how solid they perceive their skills to be in their senior year.

The wiki project in its current form is cumulative, such that new topics are added and large topics are broken into smaller pieces for further development, or "stubbed out." The authors anticipate that the wiki project could grow to such an extent that starting over with a new "home base," or main page, might be necessary after several semesters. This 
could be accomplished without deleting existing content pages by prompting students to begin work in a clean Course Page, using existing article pages as a resource like any other. Either way, author contributions are searchable by user and by date.

\section{Conclusions}

A classroom wiki for documenting social knowledge was developed by the students and used for assessment of group performance in a team-based capstone design class. Assessment feedback was collected from both corporate and academic venues. Though preliminary, the work offers novel solutions for some of the problems facing professors wishing to pursue team-based curricula, but lacking assessment tools to execute it. Results include methods of norming external-rater evaluations, promoting an active, engaged assessment environment with the students being assessed, and the development of a student-professor Rosetta Stone. Active group assessment is defined and results point to further work in demonstrating the benefits of team-based curricula in novel classroom and external environments.

References

1. Chen, H., Cannon, D., Gabrio, J. (2005). Using Wikis and Weblogs to Support Reflective Learning in an Introductory Engineering Design Course. Proceedings of the 2005 American Society for Engineering Education Annual Conference \& Exposition.

2. Courtney, J., Haynes, J., \& Paradice, D., (Eds.) (2005). Inquiring Organizations: Moving from Knowledge Management to Wisdom. Hershey, PA: Idea Group Publishing.

3. Dym, C., \& Gogino, A. (et.al) (2005). Engineering Design Thinking, Teaching and Learning. Journal of Engineering Education. 94(1) 103-121.

4. Godwin-Jones, R. (2003). Emerging Technologies, Blogs and Wikis: Environments for On-line Collaboration. Language Learning \& Technology. 7(2) 12-16.

5. Konstadakopulos, D. (2004). Learning for Innovation in the Global Knowledge Economy. Portland, OR: Intellect Books.

6. Lamb, B. (2004). Wide Open Spaces: Wikis Ready or Not. Educause Review, 39(5). Open access: www.educause.edu/ir/library/pdf/erm0452.pdf

7. Olds, B., Moskal, B., \& Miller, R. (2005). Assessment in Engineering Education: Evolution, Approaches and Future Collaborations. Journal of Engineering Education. 94(1) 13-26.

8. Pellegrino, J.W., Chudowsky, N., \& Glaser, R. (Eds.) (2001), Knowing What Students Know: The Science and Design of Educational Assessment. Washington, DC: National Academies Press.

9. Sahney, S., Banwet, D.K., \& Karunes, S. (2004). Conceptualizing Total Quality Management in Higher Education. TQM Magazine, 16(2) 145-159.

10. Tsoukas, H. (2005). Complex Knowledge: Studies in Organizational Epistemology. Oxford Press, NY. 
11. Wasserman, J., Beyerlein, S. (2005). SII Method for Assessment Reporting. Pacific Crest.

12. Wikipedia. Available online: www.wikipedia.org.

13. Wodehouse, A., \& Grierson, H. (2004). TikiWiki: A Tool to Support Engineering Design Students in Concept Generation. International Engineering and Product Design Education Conference.

14. WSU Wiki. Course page available online: http://wiki.wsu.edu/index.php/ME_416_Pezeshki

\section{Appendix A:}

Advisory Board member and Industrial Sponsor survey used to rate actual and expected performance

\begin{tabular}{|c|c|c|c|c|c|}
\hline \multicolumn{2}{|c|}{ Emerging } & \multicolumn{2}{|c|}{ Developing } & \multicolumn{2}{|c|}{ Mastering } \\
\hline 1 & 2 & 3 & 4 & 5 & 6 \\
\hline \multicolumn{6}{|c|}{ 1. Students will learn successful group interaction for a project. } \\
\hline \multicolumn{6}{|c|}{ 2. Students will learn and demonstrate written engineering communication skills. } \\
\hline \multicolumn{6}{|c|}{$\begin{array}{l}\text { 3. Students will consider safety, ethical, and other societal constraints in execution of } \\
\text { their design. }\end{array}$} \\
\hline \multicolumn{6}{|c|}{$\begin{array}{l}\text { 4. Students will have the opportunity to integrate a majority of their skills acquired in the } \\
\text { last four years regarding engineering science, design, and communication. }\end{array}$} \\
\hline \multicolumn{6}{|c|}{ 5. Students will learn appropriate corporate etiquette and a strong "customer" ethic. } \\
\hline \multicolumn{6}{|c|}{ 6. Students will learn successful project management skills. } \\
\hline 7. Stu & & 10 & & & \\
\hline
\end{tabular}

\section{Appendix B:}

Focus group questions

\section{Focus Group date: \\ Facilitated by: \\ \# participants: \\ Location:}

1. How did working with WSU Wiki compare with working with BaseCamp this semester?
a. How was it similar?
b. How was it different?
c. How well did they work together? 
2. What didn't you like about using the WSU Wiki in ME 416? Why?

3. What did you like about using the WSU Wiki in ME 416? Why?

4. How could the use of WSU Wiki in ME 416 be improved? How?

5. What did you learn from using WSU Wiki in ME 416 ?

6. Did you feel that the use of WSU Wiki in ME 416 was relevant? If so, why? If not, why not?

7. Thinking about the social, knowledge and management skills a first-year engineer needs to be successful on the job, do you feel that the Wiki project was helpful in learning those skills?

8. Do you think continuing this project — building community knowledge-- will help others?

9. I would like to invite the ME student clubs to use the wiki as a place to share their projects, history, etc. with the ME community. What do you think of this idea?

10. Are there any other groups or classes that you think might benefit from using the wiki?

11. Is there anything that you would like to add that we haven't covered?

\section{Appendix C:}

Summary of student-generated category and article pages from WSU Wiki

\begin{tabular}{|c|c|}
\hline $\begin{array}{l}\text { Social Skills } \\
\text { - } \text { - Group Member Roles } \\
\text { - } \text { Conference Calls } \\
\text { - } \text { Interpersonal communication } \\
\text { - } \text { Commun Etiquette } \\
\text { - } \text { Base Camp } \\
\text { Specification Writing } \\
\text { - Specifications } \\
\text { Negotiations } \\
\text { - } \quad \text { Buying a Car } \\
\text { - General Negotiation Skills } \\
\text { Purchases } \\
\text { - Travel Expenditures and } \\
\text { - } \text { Reimbursements } \\
\text { - } \quad \text { General Reimbursements } \\
\text { Case Studies } \\
\text { - Case Studies from your peers }\end{array}$ & $\begin{array}{l}\text { Personal Skills } \\
\text { - } \text { Interviews } \\
\text { - } \text { Resumes } \\
\text { - } \text { Public Assessment } \\
\text { - Negotiating } \\
\text { Travel } \\
\text { - Travel } \\
\text { Quality Function Deployment (QFD) } \\
\text { - Overview } \\
\text { - Customer Defined } \\
\text { - Building the House of Quality } \\
\text { Project Information } \\
\text { - Understanding your Topic } \\
\text { - Engineering Notebook } \\
\text { - Vendor Resources } \\
\text { Contact Information } \\
\text { - Dr. Chuck } \\
\text { - Jan Danforth and Secretaries } \\
\text { - WSU machine shops }\end{array}$ \\
\hline
\end{tabular}




\section{Appendix D:}

Summary of rater responses by shared category

\begin{tabular}{|c|c|}
\hline \multicolumn{2}{|c|}{ Raters identified strengths in three categories: } \\
\hline Archived knowledge & $\begin{array}{l}\text { - Captures "tribal knowledge" that would be lost. } \\
\text { - This is a great way to pass on knowledge from one } \\
\text { class to the next. } \\
\text { - Ideal for lessons learned type of indexing. } \\
\text { - If used by students. . it will not only allow students to } \\
\text { benefit from previous year work, but more importantly } \\
\text { they can see the value of setting up something like this } \\
\text { out in the "real" world. }\end{array}$ \\
\hline Peer communication & $\begin{array}{l}\text { - One strength is that much of the advice is in "student- } \\
\text { speak" so it is easily assimilated. } \\
\text { - Students will listen to what other students say. }\end{array}$ \\
\hline Flexible system & $\begin{array}{l}\text { - Readily available } 24 / 7 \text { when students want to use } \\
\text { resource. } \\
\text { - Putting information down at all is impressive. . . } \\
\text { another strength would be if it is maintained (current). }\end{array}$ \\
\hline \multicolumn{2}{|c|}{ Raters identified how to improve in three basic categories: } \\
\hline Scaffolding & $\begin{array}{l}\text { - Grasping the concept. Provide students a clear } \\
\text { understanding of the need for knowledge management, } \\
\text { some good examples, and a few descriptive survey } \\
\text { articles to read. } \\
\text { - A graded approach to quality seems particularly } \\
\text { difficult for many. }\end{array}$ \\
\hline Motivation & $\begin{array}{l}\text { - What motivates students to add information to the } \\
\text { wiki project? } \\
\text { - The challenge is to get enough information entered so } \\
\text { it becomes a valuable resource. }\end{array}$ \\
\hline Dissemination & $\begin{array}{l}\text { - Maybe student clubs can participate. Get input from } \\
\text { club members, e.g. ASME, Solar Splash, etc. } \\
\text { - It might be interesting to input some of the advice } \\
\text { given by speeches at the "Order of the Engineer" } \\
\text { dinner. } \\
\text { - Links to other resources. }\end{array}$ \\
\hline Rater insights includec & - support for including the knowledge management and \\
\hline
\end{tabular}




\begin{tabular}{|l|l|}
\hline & $\begin{array}{l}\text { social software concepts in the curriculum, benefit of } \\
\text { learning conflict resolution skills, and the need for an } \\
\text { incentive structure for graduating seniors to "leave } \\
\text { behind" their knowledge. }\end{array}$ \\
\hline
\end{tabular}

\section{Appendix E:}

Summary of student focus group responses by shared category

\begin{tabular}{|c|c|}
\hline $\begin{array}{l}\text { Compare and contrast } \\
\text { knowledge management } \\
\text { and project management }\end{array}$ & $\begin{array}{l}\text { - Most agree that "they are totally different." And that } \\
\text { they work together: "BaseCamp is better for day to } \\
\text { day management, Wiki for long-term management." } \\
\text { - Similar in that there is "a record of progress over } \\
\text { time for all steps," and "updates will remain until } \\
\text { you make changes." } \\
\text { - A few students indicated a preference of one } \\
\text { software platform over the other. }\end{array}$ \\
\hline Likes and Dislikes & $\begin{array}{l}\text { Dislikes generally related to having to learn a new } \\
\text { software, user-friendliness, lack of pre-defined } \\
\text { structure and lack of privacy. } \\
\text { - Likes generally related to helping people "down the } \\
\text { road," freedom to independently organize and } \\
\text { manage, and software flexibility, and unlimited } \\
\text { access, even after graduation. "Hopefully after we } \\
\text { graduate we can come back and use it." }\end{array}$ \\
\hline $\begin{array}{l}\text { Learning: academic and } \\
\text { professional relevance. }\end{array}$ & 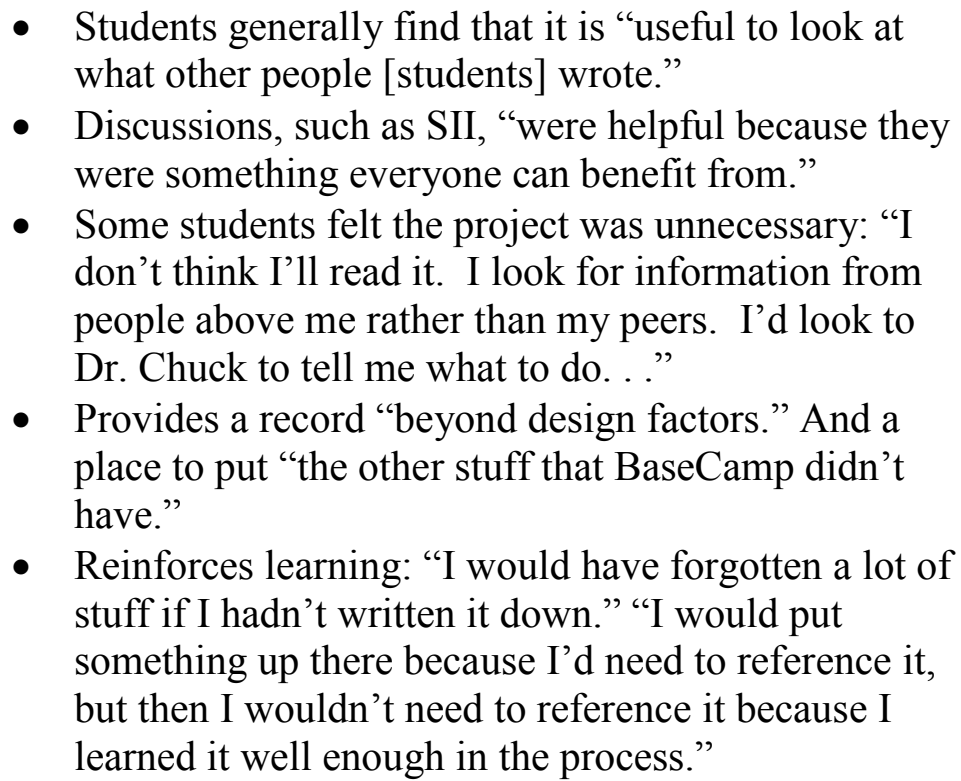 \\
\hline $\begin{array}{l}\text { Strengths of the WSU } \\
\text { Wiki Project, and why. }\end{array}$ & $\begin{array}{l}\text { - Most students found it was useful for "passing on } \\
\text { information." } \\
\text { - Prompting with activities was generally viewed as a } \\
\text { good and necessary part of the project. }\end{array}$ \\
\hline
\end{tabular}




\begin{tabular}{|c|c|}
\hline & $\begin{array}{l}\text { Supplemental materials, such as software help- } \\
\text { sheets, were helpful. }\end{array}$ \\
\hline $\begin{array}{l}\text { Suggested Improvements, } \\
\text { and how. }\end{array}$ & $\begin{array}{l}\text { - Introduce Wiki-markup earlier in the semester when } \\
\text { there isn't as much going on with projects. More } \\
\text { time to practice and look at other wikis, such as } \\
\text { Wikipedia. } \\
\text { - Other courses could benefit: "depending on the } \\
\text { teacher, Wiki might be better than the class- } \\
\text { [laughter]." }\end{array}$ \\
\hline $\begin{array}{l}\text { General insights about the } \\
\text { WSU Wiki project }\end{array}$ & $\begin{array}{l}\text { - Most students thought that continuing this project } \\
\text { will help others. } \\
\text { - Many students were unsure about the expectations } \\
\text { employers have for first-year engineers to have } \\
\text { knowledge management and project management } \\
\text { skills and how the WSU wiki project would help } \\
\text { them in their first job. } \\
\text { - Most students enthusiastically agreed that inviting } \\
\text { student clubs to use WSU Wiki is a good idea. } \\
\text { - Some students associated the Wiki project with } \\
\text { portfolio building. "The idea of a portfolio is for us } \\
\text { to work on things that interest us in our field." }\end{array}$ \\
\hline
\end{tabular}

